\title{
Diagnostic value of Beep and Yo-Yo tests in assessing physical performance of female soccer players
}

\author{
Tomasz Gabryś ${ }^{1}$, Krzysztof Stec $^{1}$, Cezary Michalski ${ }^{1}$, Wiesław Pilis ${ }^{1,2}$, Karol Pilis $^{1}$, \\ Zbigniew Witkowski ${ }^{1}$
}

${ }^{1}$ Institute of Physical Education, Tourism and Physiotherapy, Jan Dlugosz University in Czestochowa, Poland; ${ }^{2}$ Department of Physiotherapy, Opole Medical School, Opole, Poland

\section{Summary}

Study aim: The aim of the present study was to compare the physiological responses of female soccer players recorded during the Beep Test and Yo-Yo Test.

Material and methods: Twenty-three high-level women's soccer players underwent aerobic fitness testing. Modification of the Beep Test consisted of: lengthening the distance between turns to $40 \mathrm{~m}$, extending the time between the increase in speed, and including a rest period between exercise stages. During the running efforts the length of the distance run in both tests was measured as well as circulatory and respiratory variables. For statistical analyses only data obtained at maximum loads in both tests were accepted.

Results: Analyzed variables showed that all values recorded in both tests reached maximum values and did not differ statistically significantly.

Conclusion: The results show that both applied tests loaded the soccer players to a similar maximum degree and the tests are suitable for assessing the aerobic physical performance.

Keywords: Soccer players - Women - Aerobic performance - Field test

\section{Introduction}

Physical fitness in soccer is determined to a large extent by the level of aerobic metabolism [9]. The soccer players' oxygen potential is most often expressed through the classical measurement of the maximum oxygen uptake ( $\left.\mathrm{VO}_{2} \mathrm{max}\right)$ in laboratory conditions [6]. However, such measurement is difficult to perform and requires specific equipment not always available in sports training conditions, as well as specifically trained personnel. In addition, the character of the laboratory load of physical effort (monotonous running on the treadmill or cycling on the cycloergometer) does not reflect the nature of intermittent running work occurring during a soccer game. That is why field forms of testing for soccer players performing physical effort have been developed, which allow assessment of their aerobic and anaerobic fitness. Specific field tests for physical aerobic fitness include the Beep Test [24, 27] and the Yo-Yo Test [19]. Both tests are similar in their design and consist of short running sections in the field, and their specific usefulness was assessed and confirmed by laboratory measurement of $\mathrm{VO}_{2} \max [4,12,17]$. It was also noted that a good indicator of motor preparation apart from the distances covered in the directional change tests is the absolute or relative (in relation to body weight) magnitude of the developed power and the time of its maintenance at the highest level $[5,7]$. Therefore, considering the slightly different design of the Beep Test and the Yo-Yo Test, despite the fact that both tests are recommended for assessing the aerobic physical fitness of soccer players, one should be aware of their specific differences that may affect the results of the performance capacity of the subjects. In such studies, the sex of athletes should also be taken into account, as there are significant differences between men and women in the field of aerobic and anaerobic capacity and these gender differences should be taken into account in training optimization as well as in the test procedure [3]. Therefore, the purpose of the present study was to compare the physiological responses and physical performance of highly trained female soccer players, using two field-specific soccer tests (i.e. Beep Test and Yo-Yo Intermittent Endurance Test). 


\section{Material and methods}

Twenty-three healthy female soccer players (national team level) volunteered to participate in this study. Prior to participating in the study each subject was informed of the testing protocol and potential risks. This study was approved by the Regional Medical Commission prior to the initiation of data collection. The characteristics of the subjects (mean $\pm \mathrm{SD}$ ) were: age $20.68 \pm 2.39$ years, height $165.41 \pm 4.07 \mathrm{~cm}$, weight $54.62 \pm 3.55 \mathrm{~kg}$, and BMI $20.05 \pm 1.04 \mathrm{~kg} \cdot \mathrm{m}^{-2}$. Each subject completed two graded exercise tests: the modified Beep Test based on the classic Beep Test version [15] and the Yo-Yo Test [13]. Modification of the Beep Test consisted of: extending the distance between relapses to $40 \mathrm{~m}$, prolonging the time between the exercise stages to $2 \mathrm{~min}$ and raising the speed increase in the first three degrees of effort from 1 to $1.5 \mathrm{~km} / \mathrm{h}$, and introducing a 30 -second rest interval between exercise stages.

The first trial was the modified Beep Test, which consisted of running along a straight line with a length of $40 \mathrm{~m}$ and changing the running direction by 180 degrees in the opposite direction for 2 minutes at $8 \mathrm{~km} / \mathrm{h}$ with a controlled sound signal on each of these individual sections. A 2-minute run load was followed by a 30 -second rest break, and followed by a second running series at a speed of $1.5 \mathrm{~km} / \mathrm{h}$ higher. Immediately after the completion of this 2-minute run, the next 2 trials with loads increased by $1.5 \mathrm{~km} / \mathrm{h}$, but in the subsequent fourth series and the following ones the speed of the run increased by only $1 \mathrm{~km} / \mathrm{h}$. At each speed, with the exception of the last, the competitors ran for 2 minutes. The trial was continued until the maximum performance capacity of the subject was reached, i.e. running the last 40-meter section with the assumed speed. After the test, the distance traveled during its duration was calculated. After a 48-hour break, women performed the Yo-Yo Intermittent Recovery Test IR1 [13], which consisted of running a 20-meter straight line in a forward direction and, after turning 180 degrees, running in the opposite direction, followed by a 10 -second active rest. The test was started at the speed of $10 \mathrm{~km} / \mathrm{h}$, which in subsequent series increased after a 10 -second break according to a standard procedure, up to the maximum performance capacity of the subject. The speed of the traveled distances was controlled by a sound signal. When the tested athletes were not able to run the next distance with a predetermined speed, the test was completed and the length of the overall distance was calculated.

The K4b2 system (Cosmed, Italy) was used for the registration of aerobic efficiency indicators of tested soccer players. Also gas exchange variables were measured during exercise breath-by-breath, with averaging at 5-second intervals. Before each test, the $\mathrm{K} 4 \mathrm{~b} 2$ turbine flow meter was calibrated according to the manufacturer's instructions using a $3 \mathrm{~L}$ calibration syringe. The $\mathrm{O}_{2}$ and $\mathrm{CO}_{2}$ sensors were calibrated using a gas mixture $\left(15.06 \% \mathrm{O}_{2}\right.$, $5.97 \% \mathrm{CO}_{2}$ ) recommended by the manufacturer. Heart rate was recorded by a Polar Team Pro monitor (Electro OY Finland). Before and during both tests of the separate loads, the following subjects' physiological variables were recorded: heart rate (HR), number of breaths performed in 1 minute $\left(\mathrm{R}_{\mathrm{f}}\right)$, tidal volume $\left(\mathrm{V}_{\mathrm{T}}\right)$, minute pulmonary ventilation $\left(\mathrm{V}_{\mathrm{E}}\right)$, minute oxygen uptake $\left(\mathrm{VO}_{2}\right)$, minute carbon dioxide excretion $\left(\mathrm{VCO}_{2}\right)$, fraction of $\mathrm{O}_{2}$ in expired air $\left(\mathrm{FeO}_{2}\right)$, fraction of $\mathrm{CO}_{2}$ in expired air $\left(\mathrm{FeCO}_{2}\right)$. Moreover, ventilatory equivalent for oxygen $\left(\mathrm{V}_{\mathrm{E}} / \mathrm{VO}_{2}\right)$, ventilatory equivalent for carbon dioxide $\left(\mathrm{V}_{\mathrm{E}} / \mathrm{VCO}_{2}\right)$, respiratory exchange ratio (RER), and "oxygen pulse" $\left(\mathrm{VO}_{2} / \mathrm{HR}\right)$ were calculated.

For statistical analyses only data obtained at maximum loads in both tests were accepted. For the first stage means and standard deviation were calculated and later statistical analysis of all variables was carried out by assessing differences, using the t-test or Wilcoxon test for paired values. Differences were considered statistically significant at the level of $\mathrm{p}<0.05$.

\section{Results}

The distance run in the two tests was significantly different $(p<0.001)$ and in the case of the Beep Test it was $2546.17 \pm 223.11 \mathrm{~m}$, while in the case of the Yo-Yo Test it was $1147.83 \pm 281.76 \mathrm{~m}$. The circulatory and respiratory variables determined during the tests were not statistically different (Table 1). The reached values were maximal.

\section{Discussion}

The main achievement of this study was the demonstration that the two tests applied to soccer players strained the body of tested women to a similar degree. This is evidenced by physiological variables measured during the two tests, which are not essentially different. A more convenient and far more meaningful variable used to evaluate the intensity of the exercise is HR, which can also be a determinant of the occurrence of the anaerobic threshold [15, 26], and the maximum load on the body $[21,26]$. In the presented studies, the average HR reached values around $195 \mathrm{bpm}$, which with the standard deviation of 8-12 bpm indicates that some of the tested players reached the value of this variable over $200 \mathrm{bpm}$. These data indicate that in each case the maximum load on the body was reached by physical effort. Similarly, intense loads occur in match conditions in both the first and the second half, but the total time of such an intense body load in the studies of Pilis et al. 
Table 1. Statistical differences of physiological variables obtained during both test

\begin{tabular}{|c|c|c|c|c|}
\hline Variables & Test & $\mathrm{x}$ & $\pm \mathrm{SD}$ & $\mathrm{p}$ \\
\hline \multirow{2}{*}{ HR [bpm] } & Beep test & 195.41 & 10.11 & \multirow{2}{*}{ 0.991\# } \\
\hline & Yo-Yo test & 194.67 & 11.19 & \\
\hline \multirow{2}{*}{ Rf [breaths/min] } & Beep test & 57.89 & 9.31 & \multirow{2}{*}{$0.264 *$} \\
\hline & Yo-Yo test & 60.52 & 7.74 & \\
\hline \multirow{2}{*}{$\mathrm{V}_{\mathrm{T}}[1]$} & Beep test & 1.85 & 0.33 & \multirow{2}{*}{$0.837 \#$} \\
\hline & Yo-Yo test & 1.81 & 0.25 & \\
\hline \multirow{2}{*}{$\mathrm{V}_{\mathrm{E}}[1 / \mathrm{min}]$} & Beep test & 101.12 & 17.18 & \multirow{2}{*}{$0.412 \#$} \\
\hline & Yo-Yo test & 106.32 & 12.13 & \\
\hline \multirow{2}{*}{$\mathrm{VO}_{2}[\mathrm{ml} / \mathrm{min}]$} & Beep test & 2633.18 & 282.39 & \multirow{2}{*}{$0.605 \#$} \\
\hline & Yo-Yo test & 2577.15 & 447.07 & \\
\hline \multirow{2}{*}{$\mathrm{VO}_{2}[\mathrm{ml} / \mathrm{min} / \mathrm{kg}]$} & Beep test & 48.19 & 5.29 & \multirow{2}{*}{$0.779 \#$} \\
\hline & Yo-Yo test & 47.17 & 8.11 & \\
\hline \multirow{2}{*}{$\mathrm{VCO}_{2}[\mathrm{ml} / \mathrm{min}]$} & Beep test & 2668.95 & 452.89 & \multirow{2}{*}{$0.322 \#$} \\
\hline & Yo-Yo test & 2557.94 & 486.15 & \\
\hline \multirow{2}{*}{ RER } & Beep test & 1.01 & 0.10 & \multirow{2}{*}{$0.514 \#$} \\
\hline & Yo-Yo test & 0.99 & 0.05 & \\
\hline \multirow{2}{*}{$\mathrm{FeO}_{2}[\%]$} & Beep test & 17.66 & 0.64 & \multirow{2}{*}{$0.334 \#$} \\
\hline & Yo-Yo test & 17.92 & 0.59 & \\
\hline \multirow{2}{*}{$\mathrm{FeCO}_{2}[\%]$} & Beep test & 3.44 & 0.46 & \multirow{2}{*}{$0.253 *$} \\
\hline & Yo-Yo test & 3.24 & 0.54 & \\
\hline \multirow{2}{*}{$\mathrm{V}_{\mathrm{E}} / \mathrm{VO}_{2}$} & Beep test & 38.41 & 6.93 & \multirow{2}{*}{$0.264 \#$} \\
\hline & Yo-Yo test & 41.24 & 7.83 & \\
\hline \multirow{2}{*}{$\mathrm{V}_{\mathrm{E}} / \mathrm{VCO}_{2}$} & Beep test & 37.88 & 5.87 & \multirow{2}{*}{$0.128 *$} \\
\hline & Yo-Yo test & 41.56 & 6.95 & \\
\hline \multirow{2}{*}{$\mathrm{VO}_{2} / \mathrm{HR}[\mathrm{ml} / \mathrm{bpm}]$} & Beep test & 13.47 & 1.44 & \multirow{2}{*}{$0.817 \#$} \\
\hline & Yo-Yo test & 13.24 & 2.33 & \\
\hline
\end{tabular}

\# - Student test results for a paired values; * - Wilcoxon test results for a paired values.

[21] reached about 9 minutes. Attention is also drawn to the fact that the load of the players during the match may be different for people playing in various positions in the field [8]. It should also be noted that using only the HR value when assessing the impact of high-intensity physical efforts on the human body such as the Beep Test or Yo-Yo Test has, however, limited usefulness [20]. Loading the investigated women with maximum physical exertion causes that, besides achieving maximum HR, also the occurrence of maximum $\mathrm{VO}_{2}$ values was observed. The values of this variable achieved in the present study were at a high level for untrained women of similar age [1]. These values indicate that the tested athletes were not highly trained, or that soccer training does not develop this feature as much as endurance training. Reports in the literature confirm unequivocally that in soccer the dominant source of energy re-synthesis is the aerobic system, because in modern days the players during the match run more than $12 \mathrm{~km}[2,18]$ at approximately $75 \% \mathrm{VO}_{2} \max [28]$. Improving the system for resynthesis of energy by increasing $\mathrm{VO}_{2}$ max or load encountered at the anaerobic threshold by improving running economy leads to increased exercise capacity, improved technique and tactics $[10,23]$. In addition, during the 90-minute soccer game athletes perform 1000-1,400 short, very intense movements, for which energy is generated by an anaerobic energy system $[2,18]$. It means that both aerobic and anaerobic energy re-synthesis systems are the key factors determining the performance capacity in soccer.

This study also found that the tested women achieved an RER value at a level near to 1.00 at the maximum load, so they did not incur a significantly high oxygen debt and 
their metabolism should be considered aerobic and similar in intensity when reaching $\mathrm{VO}_{2} \max$ [22]. Therefore, it should be concluded that accurate tests were used to assess the aerobic physical performance of the investigated soccer players. Similar, non-statistically different values of $\mathrm{R}_{\mathrm{f}}, \mathrm{V}_{\mathrm{T}}, \mathrm{V}_{\mathrm{E}} / \mathrm{VO}_{2}, \mathrm{~V}_{\mathrm{E}} / \mathrm{VCO}_{2}, \mathrm{FeO}_{2}, \mathrm{FeCO}_{2}$ and $\mathrm{VO}_{2} / \mathrm{HR}$ recorded in this study after both tests suggest that the applied exercise load in both tests strain to a similar degree the circulatory and respiratory system of tested soccer players.

Conducted laboratory and field tests have shown that the maximum running speed is a more reliable indicator of the athlete's performance evaluation than $\mathrm{VO}_{2} \max$ and other physiological variables. This maximum running speed can be used to assess the physical performance of two players with different physiological profiles and a similar level of cardiovascular fitness [14]. Therefore, the maximum running speed or distances covered during the Beep Test or YoYo Test can be an important parameter for the assessment of physical performance in soccer, also because these tests are characterized by a change in the direction of the run and include such elements as acceleration and deceleration speed of running, running at different speeds or multiple repetitions of effort that occur in the soccer field and do not occur in laboratory tests. In the present study, the athletes ran different distances and achieved different maximum speeds in both tests, although the strain on the body of the tested soccer players in the final test phases were similar, which was confirmed by the lack of differences in the individual physiological variables. However, in the comparisons of the two tests, it is not possible to use absolute values of distance run or maximum run speeds at final loads, because the method of applying loads in the tests was different. Arazi et al. [1] believe that particularly the maximum running speed achieved during high-intensity interval exercise is a particularly useful indicator of motoric preparation in football, as it correlates with the state of body fatigue or the magnitude of anaerobic power $[16,25]$. When assessing both aerobic and anaerobic power, it is important to pay attention to the size and body composition of the subjects, which in the training process can undergo significant changes at any age, similarly to the changes developing power [11]. In the present research, female soccer players were significantly homogeneous in terms of body weight, which is why this somatic factor was not thoroughly analyzed.

\section{Conclusions}

1) The results indicate a lack of differences in the range of investigated physiological variables and suggest that the two tests used in the study can be applied interchangeably to assess the aerobic capacity of soccer players.
2) The different technical design and methodology of performing the Beep Test and the Yo-Yo Test cause that despite the different physical load achieved in both tests, stimulation of the circulatory and respiratory systems remained similar.

\section{Conflict of interest: Authors state no conflict of interest.}

\section{References}

1. Arazi H., Keihanivan A., Eatemady-Boroujeni A., Oftade A., Takhska S., Asadi A., Ramirez-Campillo R. (2017) Effects of heart rate vs. speed-based high intensity interval training on aerobic and anaerobic capacity of soccer players. Sports (Basel), 5(3): 57. DOI: 10.3390/ sports5030057.

2. Bangsbo J., Nørregaard L., Thorsoe F. (1991) Activity profile of competition soccer. Can J. Appl. Sport Sci., 16: 110-116.

3. Cardoso de Araújo M., Baumgart C., Jansen C.T., Freiwald J., Hoppe M.W. (2018) Sex differences in physical capacities of German Bundesliga soccer players. $J$. Strength Cond. Res., Advance online publication. DOI: 10.1519/JSC.0000000000002662.

4. Dourado M., Kiss M., Stangeanelli L.R., Friseli A., Daros L.B., Piaseck F. (2001) Validation of the Yo-Yo (shuttle run) intermittent test of aerobic resistance for soccer players. In: J. Mester, G. King, H. Strüder, E. Tsolakidis, A.Osterburg (eds.) Books of Abstracts of the 6th Annual Congress of the European College of Sports Science. Cologne, Germany, p. 1208.

5. Fry A.C., Kraemer W.J. (1991) Physical Performance Characteristis of American collegiate Football players. J. Appl. Sport Sci. Res., 5: 126-138.

6. Garrett W.E. Jr., Kirkendall D.T. (2000) Physiology of soccer. In: D. T. Garrett (eds.) Exercise and sport science. Williams \& Wilkins, Philadelphia (PA), Lippincott, pp. 875-884.

7. Garstecki M.A., Latin R.W., Cuppet M.M. (2004) Comparison of selected physical fitness and performance variables between NCAA Division I and II football players. J. Strength Cond. Res., 18: 292-297.

8. Gregson W., Drust B., Atkinson G., Salvo V.D. (2010) Match-to-match variability of high-speed activities in premier league soccer. Int. J. Sports Med., 31(4): 237-242.

9. Helgerud J. (1994) Maximal oxygen uptake, anaerobic threshold and running economy in women and men with similar performances level in marathons. Eur. J. Appl. Physiol. Occup. Physiol., 68: 155-161. DOI: 10.1007/ BF00244029.

10. Helgerud J., Engen L.C., Wisloff U., Hoff J. (2001) Aerobic endurance training improves soccer perfor- 
mance. Med. Sci. Sports Exerc., 33: 1925-1931. DOI: 10.1097/00005768-200111000-00019.

11. Horbacz A., Dracková D., Bukova A. (2018) The effect of two different training programs on the body composition of senior women. Phys. Activ. Rev., 6: 227-236. DOI: 10.16926/par.2018.06.27.

12. Kiss M., Vilela K., Matsushigue K., Franchini E., Martin V., Regazzini M. (2001) Aerobic power of young soccer players in treadmill and $20 \mathrm{~m}$ shuttle run tests. In: J. Mester, G. King, H. Strüder, E. Tsolakidis, A. Osterburg (eds.) Books of Abstracts of the 6th Annual Congress of the European College of Sports Science. Cologne, Germany ECSS, p. 554.

13. Krustrup P., Mohr M., Amstrup T, Rysgaard T, Johansen J., Bangsbo J. (2003) The Yo-Yo Intermittent Recovery Test: Physiological response, reliability and validity. Med. Sci. Sports Exerc., 35: 697-705.

14. Laursen P.B., Jenkins D.G. (2002) The scientific basis for high-intensity interval training. Sports Med., 32: 53-73. DOI: 10.2165/00007256-200232010-00003.

15. Léger L.A., Lambert J.A. (1982) Maximal 20m shuttle run test to predict $\mathrm{VO}_{2} \max$. Eur. J. Appl. Physiol. Occup. Physiol., 49: 1-12.

16. Lockie R.G., Dawes J.J., Jones M.T. (2018) Relationships between linear speed and lower-body power with change-of-direction speed in national collegiate athletic association divisions I and II women soccer athletes. Sports (Basel), 6(2): 30. DOI: 10.3390/sports6020030.

17. Metaxas T.I., Koutlianos N.A., Kouidi E.J., Deligiannis A.P. (2005) Comparative study of field and laboratory tests for the evaluation of aerobic capacity in soccer players. J. Strength Cond. Res., 19: 79-84.

18. Mohr M., Krustrup P., Bangsbo J. (2003) Match performance of high-standard soccer players with special reference to development of fatigue. J. Sports Sci., 21: 519-528. DOI: 10.1080/0264041031000071182.

19. Oliveira J., Magalhães J., Ascensão A., Marques A., Soares J. (2001) Sensitivity of the Yo-Yo test to monitor changes in endurance performance during the season. In: J. Mester, G. King, H. Strüder, E. Tsolakidis, A.Osterburg (eds.) Books of Abstracts of the 6th Annual Congress of the European College of Sports Science. Cologne, Germany ECSS, p. 661.

20. Paulsen K.M., Butts C.L., McDermott D.P. (2018) Observation of women soccer players' physiology during a single season. J. Strength Cond. Res., 32(6): 1702-1707. DOI: 10.1519/JSC.0000000000002025.

21. Pilis K., Stec K., Witkowski Z., Stanula A., Gabrys T., Mikołajec K. (2018) Workloads of young soccer players. In: V. Lubkina, S. Usca, A. Zvaigzne (eds.) Society, Integration, Education - Proceedings of the International Scientific Conference Society, Integration, Education, Vol. IV. Rezekne Academy of Technology, Rezekne, Latvia, RTA., pp. 199-210.

22. Ramos-Jiménez A., Hernández-TorresR., Torres-Durán P.V., Romero-Gonzalez J., Mascher D., PosadasRomero C., Juárez-Oropeza M.A. (2008) The Respiratory Exchange Ratio is Associated with Fitness Indicators Both in Trained and Untrained Men: A Possible Application for People with Reduced Exercise Tolerance. Clin. Med. Circ. Respirat. Pulm. Med., 2: 1-9.

23. Reilly T. (1994) Physiological aspects of soccer. Biol. Sport, 11: 3-20.

24. Shalfawi S.A., Haugen T., Jakobsen T.A., Enoksen E., Tønnessen E. (2013) The effect of combined resisted agility and repeated sprint training vs. strength training on female elite soccer players. J. Strength Cond. Res., 27(11): 2966-72. DOI: 10.1519/JSC.0b013e31828c2889.

25. Stanula A., Gabrys T., Szmatlan-Gabrys U., Roczniok R., Maszczyk A., Pietraszewski P. (2013) Calculating lactate anaerobic thresholds in sports involving different endurance preparation. J. Exerc. Sci. Fit., 11(1): 12-18. DOI: 10.1016/j.jesf.2012.12.001.

26. Stølen T., Chamari K., Castagna C., Wisløff U. (2005) Physiology of soccer: an update. Sports Med., 35(6): 501-536.

27. Vescovi J.D., Brown T.D., Murray T.M. (2006) Positional characteristics of physical performance in Division I college female soccer players. J. Sports Med. Phys. Fit., 46: 221-226.

28. Withers R.T., Maricic Z.W., Wasilewski S., Kelly L. (1982) Match analysis of Australian professional soccer players. J. Hum. Mov. Stud., 8: 159-176.

\section{Received 27.03.2019 \\ Accepted 22.07.2019}

(C) University of Physical Education, Warsaw, Poland 